\title{
EXPERIMENTAL ORAL CANDIDAL INFECTION AND CARRIAGE OF ORAL BACTERIA IN RATS SUBJECTED TO A CARBOHYDRATE-RICH DIET AND TETRACYCLINE TREATMENT
}

\author{
O. E. Hassan, J. H. Jones and C. Russell
}

Department of Oral Medicine, Dental School, University of Manchester

\begin{abstract}
SUMmaRY. Oral candidal infection and the carriage of oral bacteria in rats has been studied in animals on a high carbohydrate diet and treated with tetracycline. Candidal infection was not significantly enhanced by carbohydrate alone but was promoted by tetracycline; carbohydrate plus tetracycline was no more effective than tetracycline alone. Carriage of lactobacilli was enhanced by carbohydrate but streptococcal carriage was depressed; there was no effect on the number of rats carrying enterobacteria. Administration of tetracycline reduced the carriage of all three groups of bacteria but the isolation rate for enterobacteria increased towards the end of the experiment, becoming nearly the same as at the start. The prevalence of $C$. albicans did not vary with these changes in bacterial populations.
\end{abstract}

\section{INTRODUCTION}

Diet may influence the carriage of Candida albicans in the mouth. Bowen and Cornick (1970) found that the yeast disappeared from the mouths of tube-fed monkeys but reappeared when the animals were fed a high carbohydrate diet by mouth. Excess sugar may promote the growth and multiplication of yeasts (Knight and Fletcher, 1971) and when $C$. albicans was inoculated into the mouths of rats receiving a high carbohydrate diet, it persisted longer than in rats on a normal diet (Russell and Jones, $1973 a$ ). It is also noteworthy that stomatitis can be initiated in denture wearers with healthy palatal mucosa by repeated rinsing with sucrose (Olsen and Birkeland, 1976).

Tetracycline administration commonly predisposes to candidosis (Seelig, 1966a and $b$ ). In rats treated with tetracycline, candidal mycelial elements seem to penetrate the stratum corneum earlier than in untreated animals (Jones and Russell, 1973). Jones et al. (1976) found that rats treated with antibiotic and given oral inocula of $C$. albicans remained colonised longer than rats not given tetracycline. However, repeated inoculation is necessary to maintain prolonged colonisation and infection (Russell and Jones, 1975).

Tetracycline may act by interfering with the indigenous microflora which would otherwise suppress oral colonisation with C. albicans (Seelig, 1966b). In-vitro studies have shown that lactobacilli enhance (Isenberg et al., 1960) and inhibit (Young et al., 
1956) the growth of $C$. albicans. $C$. albicans was administered to germ-free and conventional chickens by Balish and Phillips (1966), who demonstrated that Escherichia coli provided protection against crop infection after oral challenge with $C$. albicans, whereas Streptococcus faecalis provided no such protection. Cormane and Goslings (1963) suggested that in-vivo interactions between $C$. albicans and bacteria arose primarily from competition for available nutrients, and that the presence of high concentrations of glucose favoured the growth of $C$. albicans. We now report a study of the effects of a carbohydrate-rich diet and tetracycline treatment on the carriage of oral bacteria in rats and its possible relationship to candidosis.

\section{MATERIALS AND METHODS}

Rats. A total of 120 Sprague-Dawley rats (males and females, average weight $100-110 \mathrm{~g}, 35$ days old) were separated into 12 groups, each of 10 rats. Groups I-IV (40 rats) were uninoculated controls and groups V-XII (80 rats) were experimental groups. The groups received the following diets: groups I, V and IX, normal diet; groups II, VI and X, carbohydraterich diet; groups III, VII and XI, normal diet plus tetracycline; groups IV, VIII and XII, carbohydrate-rich diet plus tetracycline.

Diets. The normal diet was "standard- $\frac{3}{8}$ " mouse and rat pellets (Messrs Oakes, Congleton, Cheshire). The carbohydrate-rich diet comprised powdered icing sugar $65.5 \%$, dried skimmedmilk powder $32 \%$, desiccated liver powder $2 \%$, choline chloride $0.2 \%$ and dried multivitamins ("Vitament", Beecham Animal Health, Brentford, Middlesex) $0.3 \%$. Both diets were supplied to the rats ad libitum.

Antibiotic treatment. Rats in groups III, IV, VII, VIII, XI and XII were treated with tetracycline as described by Russell and Jones $(1973 b)$. For 5 days before the experiment (week 0 ), each rat was given $40 \mathrm{ml} /$ day of a $0.1 \%$ aqueous solution of tetracycline to drink; subsequently each was given $40 \mathrm{ml} /$ day of a $0.01 \%$ solution.

Candida challenge. Rats were given oral inocula of C. albicans in the yeast phase as described by Russell and Jones (1973b). Groups V, VI, VII and VIII received C. albicans in weeks 1, 2 and 3 and groups IX, X, XI and XII in weeks 1, 2, 3, 5, 7, 9. 11 and 13 of the experiment.

Microbiological examination. In week 1 (before receiving C. albicans) and weekly to the end of the experiment, the mouth of each rat was sampled by swabbing. The swabs were streaked immediately on to three plates: (1) Rogosa SL agar (Difco), incubated in candle jars at $37^{\circ} \mathrm{C}$ for 2-3 days for the isolation of lactobacilli-representative colonies were examined by gramstained smears and tested for catalase (Cowan, 1974); (2) Mitis-Salivarius Agar (Oxoid), incubated in candle jars at $37^{\circ} \mathrm{C}$ for $48 \mathrm{~h}$-colonies were examined by gram-stained smears and tested for catalase; (3) MacConkey Agar without salt (Oxoid), incubated aerobically at $37^{\circ} \mathrm{C}$ for 24-48 $\mathrm{h}$-colonies were examined by gram-stained smears and tested for catalase and oxidase (Cowan, 1974). The swabs were then placed in $7-\mathrm{ml}$ screw-capped bottles containing $3 \mathrm{ml}$ of Sabouraud's Liquid Medium (Oxoid) with penicillin $40 \mathrm{IU} / \mathrm{ml}$ and streptomycin $20 \mu \mathrm{g} / \mathrm{ml}$ and incubated at $37^{\circ} \mathrm{C}$ until visible growth appeared, or for 2 weeks before being discarded as negative. All bottles showing growth were sub-cultured on to plates of BiGGY Medium (Oxoid) for isolation of candida. The plates were incubated for $72 \mathrm{~h}$ at $37^{\circ} \mathrm{C}$, and colonies were identified as C. albicans by the filamentation test of Taschdjian et al. (1960).

Post-mortem examination. Five rats from each group were killed 7 weeks after the beginning of the experiment; the remaining rats were killed after a further 7 weeks. The heads and tongues of all animals were examined histologically as described by Russell and Jones (1973b). Statistical comparisons between the different groups were made by the $\chi^{2}$ test (Siegel, 1956).

Statistical analysis. For each treatment group 115 swabs were examined: i.e., from 10 animals sampled eight times and from five animals sampled a further seven times. The total numbers of swabs from which a specific organism was isolated were compared group by group by the $\chi^{2}$ test (Siegal, 1956). 


\section{RESULTS}

Animals receiving the carbohydrate-rich diet remained healthy and gained weight, as did the animals on the normal diet.

\section{Carriage of C. albicans}

Results of culture are presented in table I. For the sake of brevity, only the results for weeks $0,1,4,7,9,11$ and 14 are shown. $C$. albicans was not recovered from the mouth of any rat in the control group at any time throughout the experiment, nor from any rat in the experimental groups before inoculation with the challenge strain. After inoculation, $C$. albicans was recovered from all groups for the duration of the experiment, with the exception of group V. In this group, given $C$. albicans on three occasions only and not treated with tetracycline nor provided with the carbohydraterich diet, the yeast disappeared in the seventh week. In the early stages, there was no difference in the stability of oral colonisation with $C$. albicans between groups VI, VII and VIII. At week 8, six out of 10 rats in group VI, six out of 10 in group VII and eight out of 10 in group VIII were still colonised, but, thereafter, there was a fall in the number colonised which seems less rapid in group VIII. Similarly, there was a gradual reduction in the number of rats in group IX harbouring C. albicans in their mouths; these rats were given $C$. albicans repeatedly but were fed on a normal diet and not treated with tetracycline. This reduction seemed to be more rapid than in the other groups repeatedly given $C$. albicans.

There were significant differences in the recovery of $C$. albicans between group $\mathrm{V}$ and groups VI, VII and VIII and between group IX and groups X, XI and XII $(p<0.001)$. Thus, both tetracycline treatment and the carbohydrate-rich diet favoured

TABLE I

Isolation of C. albicans from rats

\begin{tabular}{|c|c|c|c|c|c|c|c|}
\hline \multirow[b]{2}{*}{ Group* } & \multicolumn{7}{|c|}{$\begin{array}{l}\text { Percentage of rats from which } \\
\text { C. albicans was isolated in week }\end{array}$} \\
\hline & 0 & 1 & 4 & 7 & 9 & 11 & 14 \\
\hline I & 0 & 0 & 0 & 0 & 0 & 0 & 0 \\
\hline II & 0 & 0 & 0 & 0 & 0 & 0 & 0 \\
\hline III & 0 & 0 & 0 & 0 & 0 & 0 & 0 \\
\hline IV & 0 & 0 & 0 & 0 & 0 & 0 & 0 \\
\hline V & 0 & 0 & 40 & 0 & 0 & 0 & 0 \\
\hline VI & 0 & 0 & 70 & 60 & 40 & 20 & 20 \\
\hline VII & 0 & 0 & 90 & 60 & 60 & 40 & 10 \\
\hline VIII & 0 & 0 & 100 & 80 & 80 & 40 & 60 \\
\hline IX & 0 & 0 & 50 & 30 & 20 & 20 & 20 \\
\hline $\mathrm{X}$ & 0 & 0 & 70 & 60 & 80 & 60 & 60 \\
\hline XI & 0 & 0 & 80 & 80 & 100 & 100 & 100 \\
\hline XII & 0 & 0 & 100 & 100 & 100 & 100 & 100 \\
\hline
\end{tabular}

\footnotetext{
* Groups I-IV, uninoculated controls; groups V-VIII, given C. albicans in weeks 1, 2 and 3; groups IX-XII, given $C$. albicans in weeks $1,2,3,5,7,9,11$ and 13 ; groups $I, V$ and IX, normal diet; groups II, VI and X, carbohydrate-rich diet; groups III, VII and XI, normal diet plus tetracycline; groups IV, VIII and XII, carbohydrate-rich diet plus tetracycline.
} 
the oral carriage of $C$. albicans in the rats regardless of whether the challenge strain was administered once or several times. Repeated administration to rats on a normal diet, without tetracycline, also favoured persistence of the $C$. albicans.

\section{Carriage of bacteria}

Lactobacilli were found in the mouths of most rats at the beginning of the experiment but thereafter there was a gradual reduction $(p<0.001)$ in the number of tetracycline-treated rats that harboured lactobacilli, i.e., groups III, IV, VII, VIII, XI and XII, whether on the normal or the carbohydrate-rich diet, and whether given $C$. abicans or not (table II). There was an increase $(p<0.001)$ in the number of rats in

TABLE II

Isolation of lactobacilli from rats

\begin{tabular}{r|rrrrrrr}
\hline & \multicolumn{7}{|c}{$\begin{array}{c}\text { Percentage of rats from which } \\
\text { lactobacilli were isolated in week }\end{array}$} \\
\cline { 2 - 8 } Group* & 0 & 1 & 4 & 7 & 9 & 11 & 14 \\
\hline I & 60 & 60 & 70 & 60 & 60 & 60 & 80 \\
II & 70 & 80 & 80 & 90 & 100 & 100 & 100 \\
III & 60 & 50 & 50 & 20 & 0 & 0 & 0 \\
IV & 50 & 40 & 40 & 50 & 20 & 0 & 0 \\
V & 70 & 60 & 70 & 70 & 80 & 60 & 60 \\
VI & 80 & 80 & 90 & 100 & 80 & 100 & 100 \\
VII & 80 & 60 & 50 & 40 & 20 & 0 & 0 \\
VIII & 80 & 70 & 40 & 50 & 20 & 20 & 20 \\
IX & 60 & 60 & 60 & 60 & 60 & 80 & 100 \\
X & 70 & 80 & 80 & 100 & 100 & 100 & 100 \\
XI & 70 & 60 & 40 & 40 & 40 & 0 & 0 \\
XII & 70 & 60 & 30 & 40 & 60 & 20 & 20 \\
\hline & & & & & & & \\
\hline
\end{tabular}

* See footnote to Table 1.

groups II, VI and X harbouring lactobacilli, i.e., in the rats fed the carbohydrate-rich diet but not treated with tetracycline, whether inoculated with $C$. albicans or not. The stability of colonisation by lactobacilli of rats in groups I, V and IX, i.e., those fed a normal diet and not given tetracycline, remained constant throughout the experiment and was not affected by the presence of $C$. albicans.

Streptococci were found in the mouths of all the rats at the beginning of the experiment but thereafter there was a gradual reduction in the number of tetracyclinetreated rats that harboured streptococci in their mouths, and at the end of the experiment streptococci were not detectable (table III). The stability of colonisation in groups I, V and IX remained constant throughout the experiment; the presence of $C$. albicans had no effect on carriage of streptococci. The high-carbohydrate diet seemed to depress the carriage of streptococci $(\mathrm{p}<0.01)$ but the reduction was by no means as evident as when tetracycline was used.

Enterobacteria were found in the mouths of all rats at the beginning of the experiment (table IV). Subsequently, in the tetracycline-treated rats there was a gradual reduction in the numbers colonised by enterobacteria until about week 10 , 
TABLE III

Isolation of streptococci from rats

\begin{tabular}{|c|c|c|c|c|c|c|c|}
\hline \multirow[b]{2}{*}{ Group* } & \multicolumn{7}{|c|}{$\begin{array}{l}\text { Percentage of rats from which } \\
\text { streptococci were isolated in week }\end{array}$} \\
\hline & 0 & 1 & 4 & 7 & 9 & 11 & 14 \\
\hline I & 100 & 100 & 100 & 100 & 100 & 100 & 100 \\
\hline II & 100 & 100 & 80 & 70 & 100 & 100 & 100 \\
\hline III & 100 & 70 & 60 & 40 & 20 & 20 & 0 \\
\hline IV & 100 & 70 & 60 & 50 & 0 & 20 & 0 \\
\hline V & 100 & 100 & 100 & 90 & 100 & 80 & 100 \\
\hline VI & 100 & 100 & 80 & 80 & 60 & 80 & 100 \\
\hline VII & 100 & 80 & 60 & 40 & 20 & 0 & 0 \\
\hline VIII & 100 & 70 & 60 & 40 & 0 & 0 & 0 \\
\hline IX & 100 & 100 & 100 & 100 & 80 & 100 & 100 \\
\hline$X$ & 100 & 100 & 70 & 70 & 80 & 100 & 100 \\
\hline XI & 100 & 80 & 50 & 30 & 0 & 0 & 0 \\
\hline XII & 100 & 70 & 60 & 30 & 0 & 0 & 0 \\
\hline
\end{tabular}

* See footnote to table I.

TABLE IV

Isolation of enterobacteria from rats

\begin{tabular}{|c|c|c|c|c|c|c|c|}
\hline \multirow[b]{2}{*}{ Group* } & \multicolumn{7}{|c|}{$\begin{array}{l}\text { Percentage of rats from which } \\
\text { enterobacteria were isolated in week }\end{array}$} \\
\hline & 0 & 1 & 4 & 7 & 9 & 11 & 14 \\
\hline I & 100 & 100 & 100 & 90 & 80 & 100 & 100 \\
\hline II & 100 & 100 & 90 & 70 & 80 & 100 & 100 \\
\hline III & 100 & 70 & 70 & 50 & 20 & 60 & 100 \\
\hline IV & 100 & 80 & 60 & 50 & 0 & 40 & 100 \\
\hline V & 100 & 100 & 100 & 90 & 100 & 100 & 100 \\
\hline VI & 100 & 100 & 100 & 70 & 100 & 100 & 80 \\
\hline VII & 100 & 60 & 70 & 50 & 20 & 80 & 100 \\
\hline VIII & 100 & 80 & 70 & 40 & 0 & 60 & 80 \\
\hline IX & 100 & 100 & 100 & 100 & 80 & 100 & 100 \\
\hline$X$ & 100 & 100 & 90 & 70 & 80 & 100 & 100 \\
\hline XI & 100 & 70 & 60 & 40 & 20 & 60 & 80 \\
\hline XII & 100 & 80 & 60 & 40 & 0 & 20 & 80 \\
\hline
\end{tabular}

* See footnote to table I.

when the organisms reappeared. Over the 14-week period, the total number of positive swabs for each group given tetracycline was lower $(p<0.001)$ than for the corresponding control group. At the end of the experiment a similar proportion of rats in all groups harboured them, and a difference apparent in the middle of the experiment was no longer seen. E. coli was isolated and was found to be resistant to a disk containing tetracycline $25 \mu \mathrm{g}$, to which the original strain was sensitive. The stability of oral colonisation by enterobacteria in groups I, II, V, VI, IX and X remained constant throughout the experiment; neither the high-carbohydrate diet nor the presence of $C$. albicans had any effect. 


\section{Histological findings}

The treatment received by rats with histological evidence of oral candidosis is given in table V. No rat in the control groups was found to have oral candidal infection. Infection was found in all other groups except group V. This last group was given $C$. albicans only at the beginning, received a normal diet and was not given tetracycline; its members were not colonised by $C$. albicans at week 7 (table I). The numbers of sites of infection in each group are given in table II. At week 7 , infection was sometimes superficial without alteration of the lingual papillae. In contrast, in four animals (three from group XII and one from group XI, i.e., animals repeatedly given C. albicans and tetracycline), infection on the dorsal surface of the tongue was associated with loss of the lingual papillae and with a flat-surfaced hyper- or parakeratotic epithelium. At week 14, infection occurred most frequently on the dorsal surface of the tongue. In all

TABLE V

Histological evidence of candidosis in the mouth and tongue of treated rats

\begin{tabular}{|c|c|c|c|c|c|}
\hline \multirow[b]{2}{*}{ Group } & \multirow[b]{2}{*}{ Treatment } & \multicolumn{2}{|c|}{$\begin{array}{l}\text { Number of rats } \\
\text { infected }\end{array}$} & \multicolumn{2}{|c|}{$\begin{array}{l}\text { Number of sites } \\
\text { of infection }\end{array}$} \\
\hline & & wk. 7 & wk. 14 & wk. 7 & wk. 14 \\
\hline V & Initial $C$. albicans and normal diet & 0 & 0 & 0 & 0 \\
\hline VI & Initial $C$ albicans and carbohydrate-rich diet & 1 & 1 & 1 & 1 \\
\hline VII & Initial $C$. albicans, tetracycline and normal diet & 1 & 1 & 1 & 2 \\
\hline VIII & $\begin{array}{l}\text { Initial } C \text {. albicans, tetracycline and } \\
\text { carbohydrate-rich diet }\end{array}$ & 2 & 2 & 3 & 2 \\
\hline IX & Repeated $C$. albicans and normal diet & 1 & 1 & 2 & 1 \\
\hline $\mathrm{X}$ & Repeated C. albicans and carbohydrate-rich diet & 2 & 2 & 2 & 2 \\
\hline $\mathrm{XI}$ & Repeated $C$ albicans, tetracycline and normal diet & 5 & 3 & 9 & 3 \\
\hline XII & $\begin{array}{l}\text { Repeated } C \text {. albicans, tetracycline and } \\
\text { carbohydrate-rich diet }\end{array}$ & 4 & 4 & 7 & 5 \\
\hline
\end{tabular}
to IV.

5 rats were killed at week 7 and 5 at week 14. There were no sites of infection in control rats in groups I

groups at all sites of infection, the lingual papillae were replaced by a flat-surfaced layer of parakeratotic epithelium. Mycelial elements penetrated the parakeratotic layer of the epithelium but never the underlying stratum spinosum. Beneath the infected epithelium the corium was infiltrated by mononuclear cells. Sites of infection other than the tongue exhibited parakeratosis and no change in the sub-epithelial tissues was identified. These changes are similar to those described by Russell and Jones (1975) and Fisker et al. (1982). Statistical comparison between the groups showed a significant effect $(p<0.05)$ of tetracycline on the incidence of candidosis.

\section{DisCUSSION}

The present study confirmed that oral candidal infection is not easily induced in rats. Infection occurred in the mouths of only two of 20 rats given C. albicans but not given a carbohydrate-rich diet or tetracycline, in six of 20 rats on the carbohydrate-rich diet, in 10 of 20 rats treated with tetracycline and in 12 of 20 rats given a carbohydraterich diet and tetracycline. Thus, as in previous experiments (Russell and Jones, 1973), a 
positive effect of a carbohydrate-rich diet alone on infection, as distinct from carriage, was not proven $(p>0 \cdot 2)$, but tetracycline enhanced carriage and infection $(p<0.02)$. A carbohydrate-rich diet plus tetracycline did not have a greater effect than tetracycline alone on either colonisation or infection.

The promotion of candidal carriage by excess carbohydrate (table I, groups VI and $\mathrm{X}$ ) is similar to the results of previous work that showed a positive effect of glucose supplementation on growth and multiplication of $C$. albicans in saliva (Knight and Fletcher, 1971) and enhancement of the adherence of $C$. albicans to epithelial cells by sucrose (Samaranayake and MacFarlane, 1980 and 1982).

Tetracycline treatment of rats on a high-carbohydrate diet did not significantly enhance candidal carriage, presumably because of the strongly positive effect of carbohydrate alone. However histological examination indicated that infection occurred in more sites in rats treated with tetracycline and receiving the highcarbohydrate diet than in animals receiving the drug or the diet alone.

Lactobacilli were found to be equally prevalent in the mouth in all groups at the beginning of the experiments. A carbohydrate-rich diet significantly favoured the presence of lactobacilli in the rats' mouths; tetracycline treatment always reduced the carriage of these organisms. The presence of $C$. albicans did not have any effect on the carriage of lactobacilli whatever the treatment regime, nor was the occurrence of $C$. albicans affected by the presence of lactobacilli. These results suggest that lactobacilli in the mouths of rats are not significant factors in promoting or preventing candidal colonisation. It would clearly be misleading to extrapolate to the human mouth the findings in vitro of Isenberg et al. (1960) and Young et al. (1956) that suggested direct interaction between $C$. albicans and lactobacilli.

Streptococci and enterobacteria were found in the mouths of all rats at the beginning of the experiment. The carbohydrate-rich diet alone had no effect on the prevalence of enterobacteria but depressed the carriage of streptococci. Tetracycline reduced the prevalence of steptococci and of the enterobacteria, even in rats receiving the carbohydrate-rich diet. The presence of $C$. albicans did not significantly alter the prevalence of either group of bacteria. A noteworthy finding was the reappearance of enterobacteria towards the end of the experiment in rats treated with tetracycline. This reappearance was not accompanied by the disappearance of $C$. albicans. This contradicts what one might expect from the finding by Balish and Phillips (1966) that E. coli protected chickens against infection by orally-administered $C$. albicans.

The growth of resistant micro-organisms that were not identified in the present study might account for the gradual fall in the prevalence of $C$. albicans in tetracyclinetreated rats given $C$. albicans only at the start of the experiment. The findings in the present experiments relating to lactobacilli, streptococci and enterobacteria do not demonstrate any relationship between the presence or absence of these organisms and the carriage of $C$. albicans. Nevertheless, they cannot be taken as evidence to refute the widely accepted hypothesis that tetracycline promotes oral colonisation by $C$. albicans by eliminating competing bacteria. The complex interactions which may be involved have not been elucidated in this in-vivo work.

There is an apparent discrepancy between the clearly significant increase in candidal colonisation caused by the high-carbohydrate diet and the lack of a statistically significant effect on candidal infection. This may relate to a quite separate effect of carbohydrate on the influence exerted by oral bacteria on the pathogenic effect 
of $C$. albicans. For example, Hassan and Russell (1983) showed that streptococci may prevent germination of $C$. albicans but this effect is much reduced if the streptococci have been grown with sucrose.

\section{REFERENCES}

Balish E, Phillips A W 1966 Growth and virulence of Candida albicans after oral inoculation in the chick with a monoflora of either Escherichia coli or Streptococcus faecalis. Journal of Bacteriology 91:1744-1749.

Bowen W H, Cornick D E 1970 The microbiology of gingival-dental plaque. Recent findings from primate research. International Dental Journal 20:382-395.

Cormane R H, Goslings W R O 1963 Factors influencing the growth of Candida albicans (in-vivo and in-vitro studies). Sabouraudia 3:52-63.

Cowan S T 1974 Cowan and Steel's manual for the identification of medical bacteria, 2nd edn. Cambridge University Press, Cambridge.

Fisker A V, Schiott C R, Phillipsen H P 1982 Long-term oral candidosis in rats. Acta Pathologica Microbiologica Immunologica Scandinavica Section B 90:221-227.

Hassan O, Russell C 1983 The effect of oral bacteria on the germination of Candida albicans. Journal of Dental Research 62:430, Abst. 136.

Isenberg H D, Pisano M A, Carito S L, Berkman J I 1960 Factors leading to overt monilial disease. I. Preliminary studies of the ecological relationship between Candida albicans and intestinal bacteria. Antibiotics and Chemotherapy 10:353-363.

Jones J H, Russell C 1973 The histology of chronic candidal infection of the rat's tongue and its relevance to human oral leukoplakia. Journal of Clinical Pathology 26:390.

Jones J H, Russell C, Young C, Owen D 1976 Tetracycline and the colonisation and infection of the mouths of germ-free and conventionalised rats with Candida albicans. Journal of Antimicrobial Chemotherapy 2:247-253.

Knight L, Fletcher J 1971 Growth of Candida albicans in saliva: Stimulation by glucose associated with antibiotics, corticosteroids and diabetes mellitus. Journal of Infectious Diseases 123:371-377.

Olsen I, Birkeland J M 1976 Initiation and aggravation of denture stomatitis by sucrose rinses. Scandinavian Journal of Dental Research 84:94-97.

Russell C, Jones J H 1973a The effects of oral inoculation of the yeast and mycelial phases of Candida albicans in rats fed on normal and carbohydrate-rich diets. Archives of Oral Biology 18:409-412.

Russell C, Jones J H $1973 b$ Effects of oral inoculation of Candida albicans in tetracycline-treated rats. Journal of Medical Microbiology 6:275-279.

Russell C, Jones J H 1975 The histology of prolonged candidal infection of the rat's tongue. Journal of Oral Pathology 4:330-339.

Samaranayake L P, MacFarlane T W 1980 An in-vitro study of the adherence of Candida albicans to acrylic surfaces. Archives of Oral Biology 25:603-609.

Samaranayake L P, MacFarlane T W 1982 The effect of dietary carbohydrates on the in-vitro adhesion of Candida albicans to epithelial cells. Journal of Medical Microbiology 15:511517.

Seelig M S $1966 a$ Role of antibiotics in the pathogenesis of candida infections. American Journal of Medicine 40:887-917.

Seelig M S $1966 b$ Mechanisms by which antibiotics increase the incidence and severity of candidiasis and alter the immunological defenses. Bacteriological Reviews 30:442-459.

Siegel S 1956 Nonparametric statistics for the behavioural sciences. McGraw-Hill, New York.

Taschdjian C L, Burchall J J, Kozinn P J 1960 Rapid identification of Candida albicans by filamentation on serum and serum substitutes. American Journal of Diseases of Children 99:212-215.

Young G, Krasner R I, Yudkofsky P L 1956 Interactions of oral strains of Candida albicans and lactobacilli. Journal of Bacteriology 72:525-529. 